\title{
Three dimensional measurements of the palate using a semiconductor laser: The influence of anterior cross bite on the palate in deciduous dentition
}

\author{
Mikio Kato, Michiyo Ito, Tsutsu Niito, Eiki Kato, Harumi Ishikawa and Michiharu Daito \\ Department of Pediatric Dentistry, Osaka Dental University \\ 1-5-17 Otemae, Chuo-ku, Osaka 540-0008, JAPAN
}

\begin{abstract}
The objective of the study was to make three dimensional measurements of the maxillary palate of 3- and 4-year old children who have developed anterior cross bite of deciduous dentition using a semiconductor laser. The effects of anterior cross bite were examined on the interdentition section area, the intradentition projection area, and the palate volume. Compared with normal occlusion, anterior cross bite of deciduous dentition caused smaller interdentition section areas at the deciduous canines and the primary first molars, and greater interdentition section areas at the primary second molars and between the posterior margins of the primary second molars. The intradentition projection area at the anterior dentition was smaller in anterior cross bite than in normal occlusion. The intradentition projection area at the posterior dentition in anterior cross bite was nearly the same as that in normal occlusion. The anterior palate volume was smaller and the posterior palate volume was greater in anterior cross bite than in normal occlusion. The above results suggest that anterior cross bite in deciduous dentition suppresses anterior growth and accelerates posterior growth of the maxillary palate.
\end{abstract}

\section{Key words}

Anterior cross bite, Deciduous dentition, Palate,

Semiconductor laser,

Three dimensional measurements

\section{Introduction}

Occlusal abnormalities occurring in the deciduous dentition period include anterior cross bite, apertognathia, deep bite, maxillary protrusion and posterior cross bite ${ }^{1,2)}$. The anterior cross bite of deciduous dentition is relatively prevalent among the Japanese and interferes greatly with normal growth of maxillary deciduous dentition. Suppression of the growth of maxillary anterior dentition inhibits the subsequent normal growth of permanent anterior dentition. Accordingly, anterior cross bite is treated in its early stages by pediatric dentists using chin caps, FKO, lingual arch and maxillary traction devices ${ }^{3)}$. In anterior cross bite of deciduous dentition, the palatal configuration changes from the normal configuration.

Received on October 8, 2009

Accepted on December 14, 2009
Therefore, it is thought that, in anterior cross bite, the interdentition section area, the intradentition projection area and the palate volume differ greatly from normal. We used a semiconductor laser to make three dimensional measurements of the palate with anterior cross bite of deciduous dentition ${ }^{4}$. We examined the influences of anterior cross bite on the interdentition section area, the intradentition projection area, and the palate volume.

\section{Materials and Methods}

\section{Materials}

In the present study, we made three dimensional measurements of the palate. Three dimensional measurements of the palates of normal maxillary primary dentition (hereinafter referred to as normal occlusion) in children was done for 3- and 4-year old Japanese children ( 5 boys and 5 girls for each 

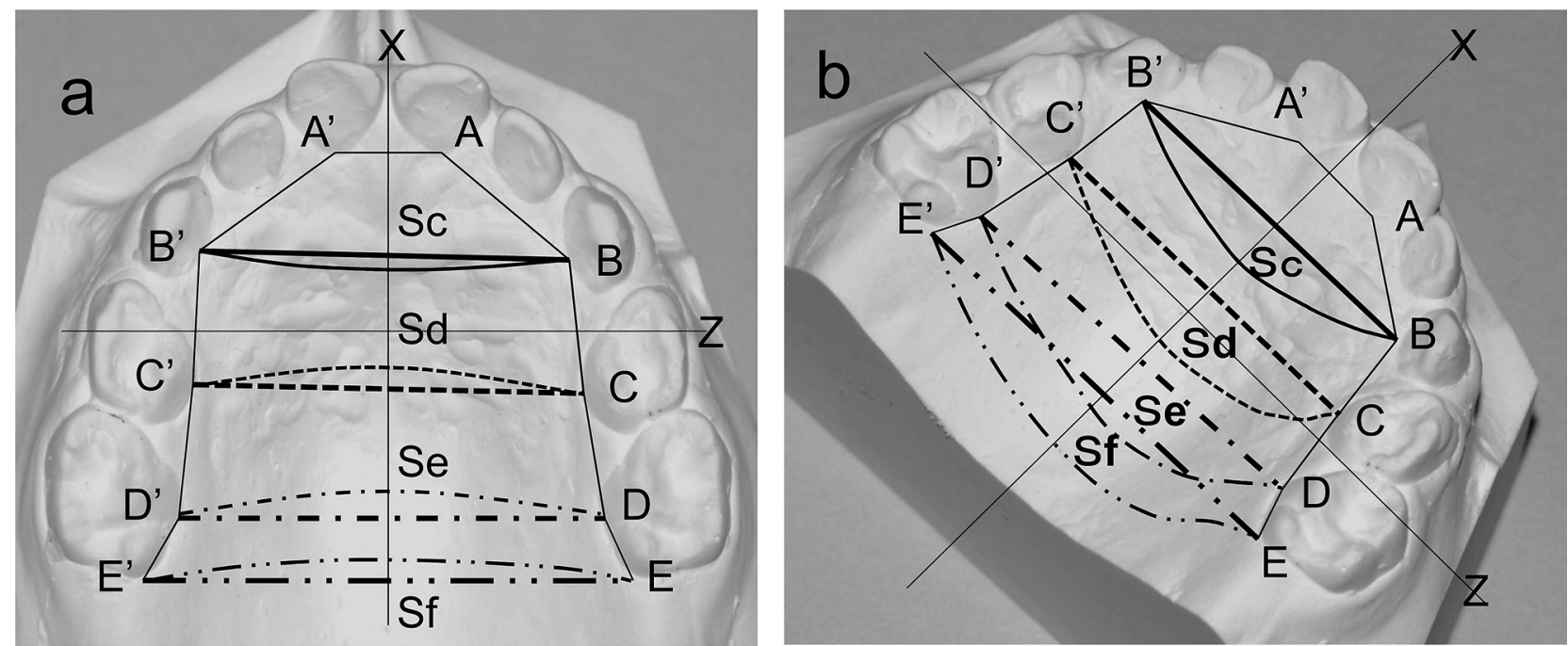

Fig. 1 The positions of the measurement points of the palate and the portions of the palate section areas ( $\mathrm{Sc}, \mathrm{Sd}, \mathrm{Se}$ and $\mathrm{Sf}$ ) on the maxillary primary dentition plaster model

$\mathrm{a}$ : The figure based on the palate plane, $\mathrm{b}$ : The figure rotated $45^{\circ}$ around the $\mathrm{x}$ axis and the $\mathrm{z}$ axis of the figure based on the palate plane

age) using a semiconductor laser ${ }^{4}$.

We studied patients who visited the pediatric dental clinic, Osaka Dental University Hospital, 10 cases ( 5 boys and 5 girls) of 3 - and 4 -year old children who had cross bite in their deciduous dentition. Impressions of maxillary primary dentition of these patients were taken using impression materials, and models of the maxillary arch were prepared.

\section{Methods}

First, the whole maxillary arch model was recognized in the semiconductor laser as a three dimensional form. Next, utilizing the configuration measurement program of the semiconductor laser, the following ten points were plotted: the lowest points of the bilateral maxillary primary central incisors at the cervical portion of the palate (Fig. 1, A and A'), the bilateral $C_{L}$ (the width of the lingual cervical line of the deciduous canines on both sides, B and B'), the bilateral $D_{L}$ (the width of the lingual cervical line of the first deciduous molars on both sides, $\mathrm{C}$ and $\mathrm{C}^{\prime}$ ), the bilateral $\mathrm{E}_{\mathrm{L}}$ (the width of the lingual cervical line of the second deciduous molars on both sides, D and D') and the end points of the posterior margin of the bilateral maxillary primary second molars on the palatal side (E and E'). Thereafter, palate section areas, palate projection areas and palate volumes were calculated using the configuration analysis program. We used KaleidaGraph Ver. 4.0, Hulinks Corp., USA for statistics processing.
1) Palate section areas

(1) Palate section area of the width of the deciduous canines

The area comprising (i) the straight line B-B' connecting the lowest points of the bilateral maxillary deciduous canines at the cervical portion of the palate and (ii) the straight line on the palatal surface directly under B-B'. The area is framed by __ in Fig. 1. Hereafter, this is expressed as Sc.

(2) Palate section area of the width of the primary first molars

The area comprising (i) the straight line C-C' connecting the lowest points of the bilateral maxillary primary first molars at the cervical portion of the palate and (ii) the straight line on the palatal surface directly under C-C'. The area is framed by ------ in Fig. 1 and hereafter will be expressed as $\mathrm{Sd}$.

(3) Palate section area of the width of the primary second molars

The area comprising (i) the straight line D-D' connecting the lowest points of the bilateral maxillary primary second molars at the cervical portion of the palate and (ii) the straight line on the palatal surface directly under D-D'. The area is framed by $-\cdot-\cdot-$ in Fig. 1. Hereafter, this will be expressed as Se.

(4) Palate section area of the width of the primary second molars distal edge

The area comprising (i) the straight line E-E' connecting the posterior margin points of the bilateral maxillary primary second molars at the palate and 
(ii) the straight line on the palatal surface directly under E-E'. The area is framed by $-\cdots-$ in Fig. 1. Hereafter, this will be expressed as Sf.

2) Palate projection areas

(1) Anterior palate projection area

The area of the polygon connecting points $\mathrm{A}, \mathrm{B}, \mathrm{C}$, C' and B' and A'-A. Hereafter, this will be expressed as $\mathrm{Sa}$.

(2) Posterior palate projection area

The area of the polygon connecting points $\mathrm{C}, \mathrm{D}, \mathrm{E}$, E' and D' and C'-C. Hereafter, this will be expressed as $\mathrm{Sb}$.

3) Palate volumes

(1) Anterior palate volume

The volume comprising $\mathrm{Sa}$ and the palate surface area directly under Sa, hereafter expressed as Va.

(2) Posterior palate volume

The volume comprising $\mathrm{Sb}$ and the palate surface area directly under $\mathrm{Sb}$, hereafter expressed as $\mathrm{Vb}$.

To investigate changes in the configuration of the palate induced by cross bite, we compared palate section areas, palate projection areas and palate volumes for normal maxillary primary dentition and for maxillary primary dentition ${ }^{5-8)}$.

\section{Results}

1) Comparisons of palate section areas $(\mathrm{Sc}, \mathrm{Sd}, \mathrm{Se}$ and $\mathrm{Sf}$ )

The Sc area was $25.8 \mathrm{~mm}^{2}$ for the anterior cross bite in comparison with $54.3 \mathrm{~mm}^{2}$ in normal occlusion ${ }^{4}$, indicating that the palate section area of the width of the deciduous canine was smaller in the anterior cross bite condition. The $\mathrm{Sd}$ area was $121.7 \mathrm{~mm}^{2}$ for the anterior cross bite in comparison with $140.9 \mathrm{~mm}^{2}$ in normal occlusion ${ }^{4)}$, indicating that the palate section area of the width of the primary first molar was smaller for the anterior cross bite. However, the Se area was $214.3 \mathrm{~mm}^{2}$ for the anterior cross bite in comparison with $177.5 \mathrm{~mm}^{2}$ in normal occlusion ${ }^{4}$, indicating that the palate section area of the width of the secondary primary molar was greater for the anterior cross bite. The Sf area was $243.0 \mathrm{~mm}^{2}$ for the anterior cross bite in comparison with $211.0 \mathrm{~mm}^{2}$ in normal occlusion ${ }^{4)}$, indicating that the palate section area of the width of the primary second molar was greater for the anterior cross bite.

Mann-Whitney's U test was used to compare the palate section areas for the anterior cross bite and for the normal bite, A two-tailed $P$ value was considered statistically significant (Fig. 2).

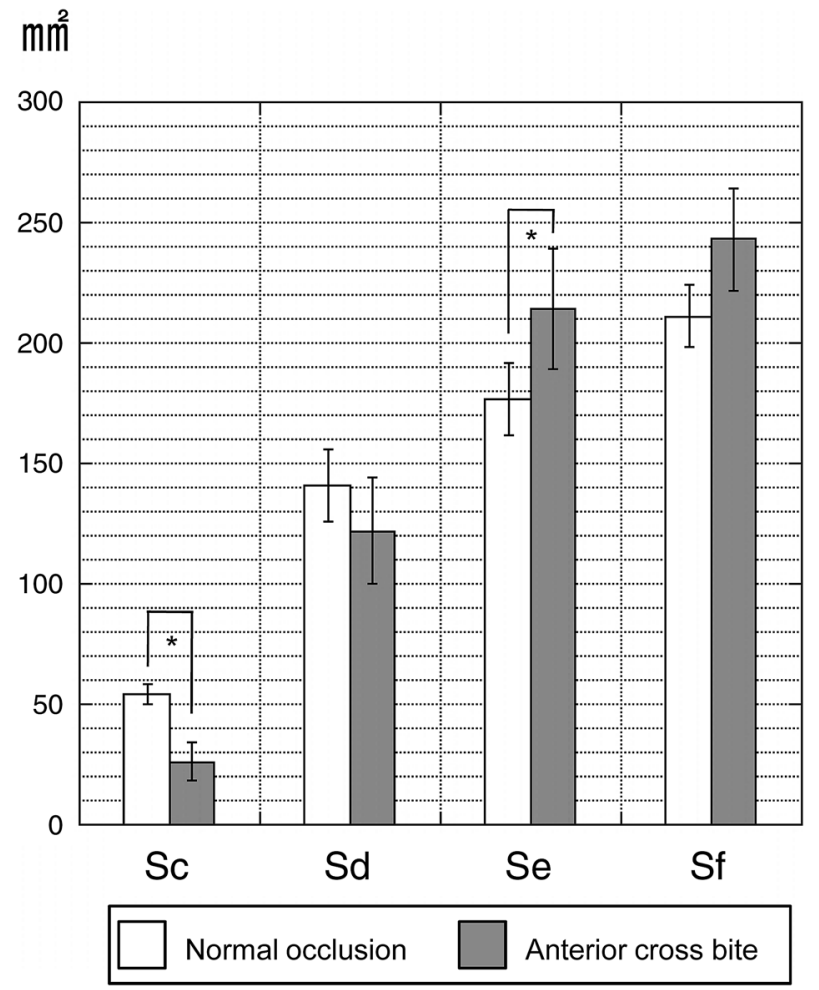

Fig. 2 The results of the measurements of the palate section area in the normal occlusion and the anterior cross bite Significant difference between two groups; ${ }^{*} P<0.05$

2) Comparisons of palate projection areas ( $\mathrm{Sa}$ and $\mathrm{Sb})$

The Sa was $280.3 \mathrm{~mm}^{2}$ for the cross bite in comparison with $309.8 \mathrm{~mm}^{2}$ in normal occlusion ${ }^{4}$, indicating that the anterior palate projection area was smaller for the anterior cross bite. The Sb was $283.3 \mathrm{~mm}^{2}$ for the anterior cross bite in comparison with $293.0 \mathrm{~mm}^{2}$ in normal occlusion ${ }^{4}$, both being similar.

Mann-Whitney's U test was used to compare the palate section area of $\mathrm{Sa}$ and $\mathrm{Sb}$ for the anterior cross bite and the normal bite. A two-tailed $P$ value was not significant (Fig. 3).

3) Comparisons of palate volumes ( $\mathrm{Va}$ and $\mathrm{Vb}$ )

The Va volume was $666.6 \mathrm{~mm}^{3}$ for the anterior cross bite in comparison with $708.8 \mathrm{~mm}^{3}$ in normal occlu$\operatorname{sion}^{4)}$, indicating that the anterior palate volume was smaller for the anterior cross bite. The $\mathrm{Vb}$ volume was $2,497.5 \mathrm{~mm}^{3}$ for the anterior cross bite in comparison with $2,372.3 \mathrm{~mm}^{3}$ in normal occlusion ${ }^{4}$, indicating that the posterior palate volume was greater for the anterior cross bite.

Mann-Whitney's U test was used to compare palate volumes $\mathrm{Va}$ and $\mathrm{Vb}$ for the anterior cross bite 


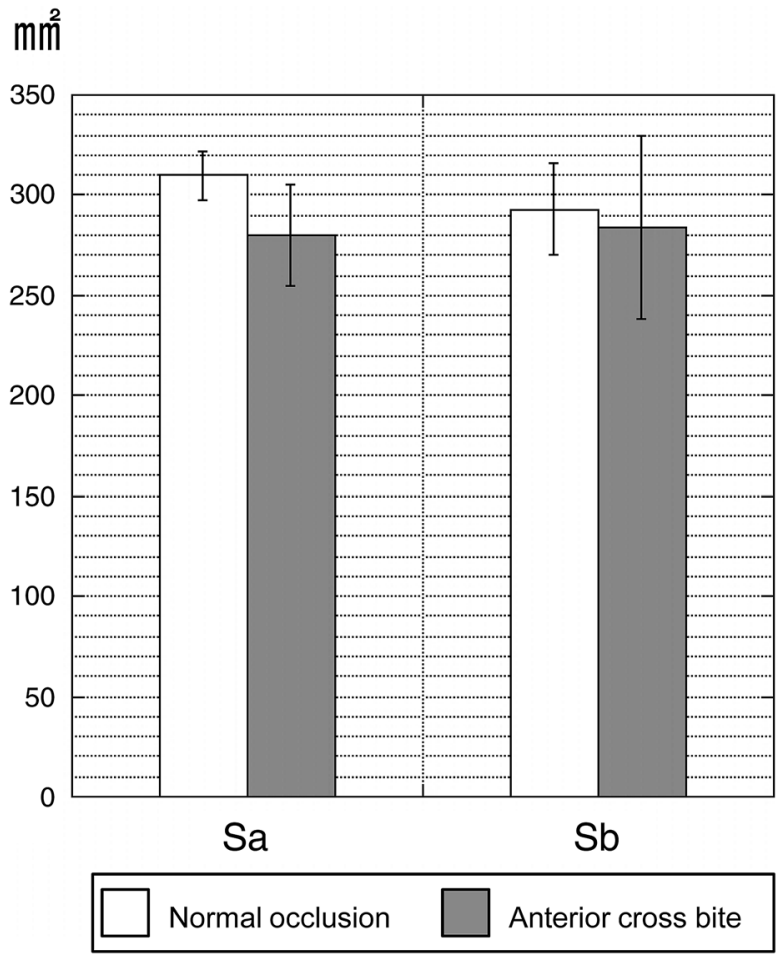

Fig. 3 The results of the measurements of the palate projection area in the normal occlusion and the anterior cross bite

There were no significant differences between two groups.

and the normal bite. A two-tailed $P$ value was not significant (Fig. 4).

\section{Discussion}

1) Comparisons of palate section areas ( $\mathrm{Sc}, \mathrm{Sd}, \mathrm{Se}$ and Sf)

The interdentition section areas $\mathrm{Sc}$ and $\mathrm{Sd}$ were smaller for anterior cross bite than for normal deciduous dentition. It appears that in the former, the maxillary anterior dentition is pushed dorsad, causing a shallower palate. Conversely, the interdentition section areas Se and Sf were larger for anterior cross bite, suggesting that the posterior portion of the palate became deeper as the anterior portion of the palate was pushed down.

The interdentition section areas Sc and Sd were smaller for anterior cross bite than for normal occlusion, suggesting that the palate was compressed by dorsad pressure on the maxillary anterior dentition, and the palate became shallower due to dorsad compression of the incisive bones. The suppression of the growth of the anterior portion of the maxillary palate interfered with the growth of the upper jaw,

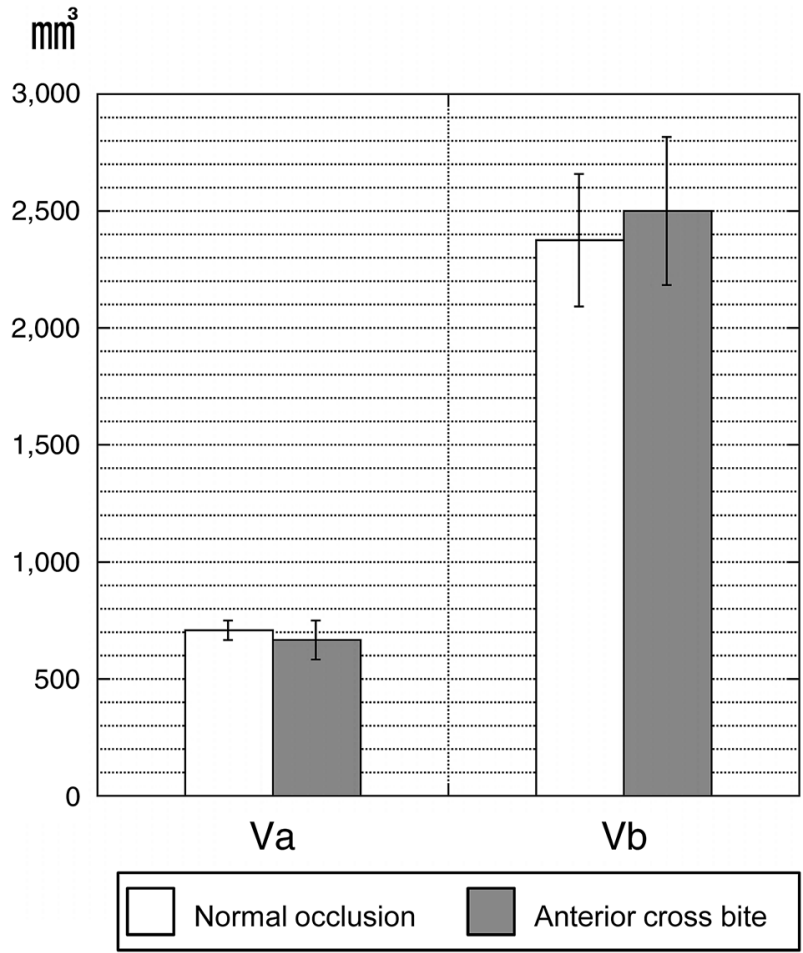

Fig. 4 The results of the measurements of the palate volume in the normal occlusion and the anterior cross bite

There were no significant differences between two groups.

resulting in a shallower palate. The interdentition section areas $\mathrm{Se}$ and $\mathrm{Sf}$ were greater for anterior cross bite than for normal occlusion, suggesting that the anterior growth of the posterior portion of the palate was suppressed, causing a cranial shift of the palatal growth and resulting in a deeper palate ${ }^{9,10)}$.

2) Comparisons of palate projection areas ( $\mathrm{Sa}$ and $\mathrm{Sb})$

The intradentition projection areas Sa were smaller for anterior cross bite than for normal deciduous dentition. It appears that in the former, the deciduous dentition was compressed dorsad. In other words, the maxillary anterior dentition retreated dorsad, resulting in smaller intradentition projection areas $\mathrm{Sa}$ for anterior cross bite. The configuration of dentition changed from a semicircular shape to a U shape.

The intradentition projection area $\mathrm{Sb}$ for anterior cross bite was nearly the same as that in normal occlusion. It appears that the deciduous molars are hardly affected by the pressure from the deciduous anterior dentition.

3) Comparisons of palate volumes ( $\mathrm{Va}$ and $\mathrm{Vb}$ )

The palate volume Va was smaller for anterior cross 
bite than for normal occlusion. It is thought that in the former, the anterior portion of the palate is pushed up. Conversely, the palate $\mathrm{Vb}$ was greater for anterior cross bite. It is thought that the posterior portion of the palate is pushed down. For deciduous dentition with anterior cross bite, it appears that the anterior growth of the anterior portion of the palate is suppressed, interfering with anterior growth, accelerating cranial growth of the posterior portion of the palate, and resulting in greater palate volume ${ }^{11-14)}$.

Based on the above findings, we conclude that three dimensional measurements using a semiconductor laser is very useful in the examination and diagnosis of pediatric palates having anterior cross bite in the deciduous dentition period. This method can be utilized in treatment planning and confirmation of outcomes by comparison with normal palates.

\section{References}

1) Jeffery, A.D., Ralph, E.M. and David, R.A.: Managing the developing occlusion. In: Dentistry for the Child and Adolescent. 8th ed. CV Mosby Company, St. Louis, 2004, pp. 651-656.

2) Ide, M., Moriyasu, K., Takahashi, T., Takamizawa, Y., Hoshi, M., Ishikawa, Y. and Ohmori, I.: A clinicstatistical survey on incidence and treatment of malocclusion at the pediatric dental clinic of the Tsurumi University Dental Hospital (the third report). Jpn J Ped Dent 38: 795-802, 2000. (in Japanese)

3) Susami, R.: Rinshou-hantaikougou. 1st ed. Ishiyaku Publishers, Inc., Tokyo, 1997, pp. 137-172.

4) Kato, M., Okuda, M., Ichiyanagi, S., Tsuge, M., Kato, E., Kuyama, K., Fujita, N. and Daito, M.: Three dimensional measurement of the palate using the semiconductor laser. 1. Changes in the palate section areas, palate projection areas and palate volumes in the deciduous dentition according to age. Jpn J Ped Dent 44: 641-648, 2006. (in Japanese)
5) Kusaki, J.: A study on development of the palatal forms during deciduous dentition by moiré topography. Shigaku 70: 85-98, 1982. (in Japanese)

6) Sakai, M., Saiki, T., Ohotani, A., Ohotani, A., Yamamoto, A. Ichikawa, M. and Kusachi J.: A study on the volume of palate during deciduous dentition by moiré topography. Odontology 69: 1183-1184, 1982. (in Japanese)

7) Ohmura, T.: A study on the forms and the volume of the palate for deciduous dental arch period (IIA) and permanent dental arch period (IIIC) with the same person - An application of moiré topography-. Shigaku 65: 740-751, 1991. (in Japanese)

8) Marugame, T., Hayasaki, H., Watanabe, R., Fujisaki, M., Yamasaki, Y. and Nakata, M.: Three dimensional treatment changes of the maxillary and palate on deciduous crossbite. Jpn J Ped Dent 35: 790-798, 1997. (in Japanese)

9) Sakai, M., Suda, M., Uesugi, S., Nanba, M., Miyao, M. and Takahashi, K.: Palatal forms in deciduous dentition observed in the cases of normal occlusion, reversed occlusion and maxillary protrusion. Jpn $J$ Ped Dent 16: 321-325, 1978. (in Japanese)

10) Sakai, M., Saiki, T., Ichikawa, M., Ohotani, A., Mochizuki, M. and Kusachi, J.: Changes in palatal forms following correction of anterior crossbite of deciduous dentition by moiré topography. Odontology 69: 988-996, 1981. (in Japanese)

11) Tsai, H.H.: Components of anterior crossbite in the primary dentition. ASDC J Dent Child 68: 27-32, 2001.

12) Nagahara, K., Murata, S., Nakamura, S. and Tsuchiya, T.: Prediction of the permanent dentition in deciduous anterior crossbite. Angle Orthod 71: 390-395, 2001.

13) Shimomura, J., Tanabe, T., Taguchi, Y., Shimooka, S. and Noda, T.: Anterior crossbite in the primary dentition: proposal for a new analytical method in children. Odontology 93: 56-60, 2005. (in Japanese)

14) Primozic, J., Ovsenik, M., Richmond, S., Kau, C.H. and Zhurov, A.: Early crossbite correction: a threedimensional evaluation. Eur J Orthod 31: 352-356, 2009. 